\title{
SCIDOC
}

International Journal of Dentistry and Oral Science (IJDOS)

ISSN: 2377-8075

\section{Prevalence Of Partial Anodontia In The South Indian Population}

Jannathul Feridoz .K ${ }^{1}$, Nikita Sivakumar ${ }^{2}$, A. Sumathi Felicita ${ }^{3}$, Anandhi .T ${ }^{4}$, Dhanraj Ganapathy ${ }^{5 *}$

${ }^{1}$ Intern, Department of Prosthodontics, Saveetha Dental College and Hospitals, Chennai -600 077, India.

${ }^{2}$ Intern, Department of Prosthodontics, Saveetha Dental College and Hospitals, Chennai -600 077, India.

${ }^{3}$ Reader, Department of Orthodontics, Saveetha Dental College and Hospitals, Chennai -600 077, India.

${ }^{4}$ Lecturer, Department of Radiology, Saveetha Dental College and Hospitals, Chennai-600 077, India.

${ }^{5}$ Professor and Head, Department of Prosthodontics,Saveetha Dental College, Chennai, India.

\section{Abstract}

Background: To date, there are very few studies regarding the impacted teeth, eruption status in South Indian population. This study aims to analyse the eruption status of the teeth and also the reasons behind their impactions.

Aim: To study the prevalence of partial anodontia namely missing and impacted teeth in South Indian population

Materials and methods: Status of impacted teeth was evaluated radiographically for 500subjects (250males and 250 females) and the impaction status, eruption status and congenital missing teeth were recorded. Statistical analysis used to access point prevalence.

Results: Out of the 500 patients only 323 patients (64.6\%) had a full complement of teeth. In 177 patients (35.4\%) there was failure of eruption with impaction of teeth and 14 patients $(2.8 \%)$ had congenitally missing teeth,26 patients $(5.2 \%)$ had retained deciduous teethand 48 patients $(9.6 \%)$ had impacted teeth due to retained deciduous teeth.

Conclusion: This study on the south Indian population analysed prevalence of partial anodontia and showed a greater prevalence on females compared to males. Prevalence of impaction is most common in South Indian population compared to Congenital missing and retained deciduous tooth.

\section{Introduction}

Nature tries to eliminate anything that is not in use which is of universal fact. Likewise with the evaluation of civilisation, the use of refined and soft diet has completely eliminated the need for a strong and large jaw for mastication and jaw movements [1].

Hence, with evolution, human jaws have shrunk from its large ape size to a smaller one and thus, there is no space in our mouths in order to accommodate all 32 teeth. Therefore, the teeth that develop are most often impacted due to lack of space. An impacted tooth is a tooth that is prevented from erupting into its rightful position in the oral cavity because of lack of space, malpositioned tooth or other impediments. This can be attributed to racial variation in the pattern of facial growth, jaw, and tooth size, which are crucial determinants of the eruption pattern.Peterson characterised impacted teeth as those teeth that fails to erupt into the dental arch within the expected time of eruption [2]. Farman stated later that impacted teeth are those teeth that are prevented from eruption due to a physical barrier within the path of eruption.Generally, all the permanent tooth erupt between the ages of 6 and 21 years band their eruption time varies with races [3].

The main objective of this study was to evaluate the prevalence of partial anodontiain south Indian population within the age group of $10-45$ years in males and females.

\section{Materials and Method}

The population studied consisted of a total of 500 patients (250males, 250females) who visited saveetha dental college and hospital, belonging to south India within the age of 11-45 years.

The inclusion criteria were as follows:

- Patients aged years 11-45 years

- Patients who had no history of extraction

- Patients who are non syndromic

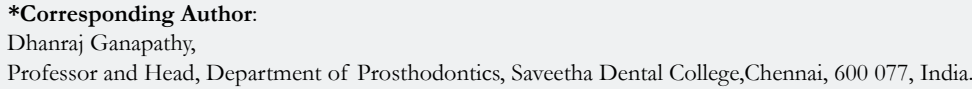

Citation: Jannathul Feridoz .K, Nikita Sivakumar, A. Sumathi Felicita, Anandhi .T, Dhanraj Ganapathy. Prevalence Of Partial Anodontia In The South Indian Population. Int J Dentistry Oral Sci. 2021;8(1):1405-1408. doi: http://dx.doi.org/10.19070/2377-8075-21000279

Copyright: Dhanraj Ganapathy ${ }^{\circ} 2021$. This is an open-access article distributed under the terms of the Creative Commons Attribution License, which permits unrestricted use, distribution and reproduction in any medium, provided the original author and source are credited. 
- Patients who are systemically healthy

- Patients ho had no traumatic history

Digital Orthopantomograms (OPG) were collected retrospectively from the Department of Radiology. The radiographs were analysed and interpreted for the following:

1.Impacted maxillary and mandibular permanent teeth excluding third molars

2.Gender of the patient

3.Retained deciduous teeth due to impaction

4.Congenital Missing teeth

5. Delayed tooth development

Third molars were not evaluated as these have been studied by numerous authors.

The data obtained were tabulated ans subjected to statistical evaluation.

\section{Result}

The study population consisted of 500 patients whose age ranged from 11-45 years. There were 250 males and 250 females. Out of the 250 male and 250 female patients 323 patients $(64.6 \%)$ has completely erupted teeth with no impaction and 177 patients (35.4\%) failed to erupt completely and there was a impaction of Canines,lateral incisors and molars in that $91(36.4 \%)$ are females $86(34.4) \%$ are males (Fig 1). $26(5.2 \%)$ patients has retained decid- uous teeth in that $14(5.6 \%)$ are females $12(4.8 \%)$ are males which is commonly of lower incisors, canines and molars. (Fig 2).14 $(2.8 \%)$ patients has Congenital missing teeth in that $8(3.2 \%)$ are females $6(2.4 \%)$ are males which is commonly missing teeth are premolars and lateral incisors (Fig 3). 24(4.8\%) patients has Delayed tooth development after crossing age limit in that $13(5.2 \%)$ are females $11(4.4 \%)$ are males which is commonly of central incisors and canines (Fig 4). 48(9.6\%) patients has impacted teeth along with retained deciduous teeth in that 26(10.4\%) are females $22(8.8 \%)$ are males which is commonly of canines and premolars (Fig 5). The arch wise distribution of impaction in this study showed greater predilection towards mandible 130 (52\%) than the maxilla $120(48 \%)$.

The most commonly impacted teeth were canines and premolars followed by lateral incisors ( $\mathrm{p}$ value $<0.001$ which is statistically significant). Gender wise distribution of impaction showed a predilection towards females $91(36.4 \%)$ than males 86 (34.4\%.). Congenital missing of teeth was more common in females $8(3.2 \%)$ than in males $6(2.4 \%)$.

\section{Discussion}

There are very few studies regarding the impaction, retained deciduous, Congenital missing of teeth in South Indian population within the 11-45 age group. This study aimed to analyse the prevalence of impaction,retained deciduous and Congenital missing of teeth and also the reason behind their impactions which can be

Table 1. Distribution of anodontia.

\begin{tabular}{|c|c|c|c|}
\hline & Total (500) & Female(250) & Male(250) \\
\hline Impacted & $177(35.4 \%)$ & $91(16 \mathrm{~A} \%)$ & $86(34.4 \%)$ \\
\hline Retained deciduous & $26(5.2 \%)$ & $14(5.6 \%)$ & $12(4.8 \%)$ \\
\hline Congenital Mising & $14(2.8 \%)$ & $8(3.2 \%)$ & $6(2.4 \%)$ \\
\hline $\begin{array}{c}\text { Delayed tooth } \\
\text { development }\end{array}$ & $24(4.8 \%)$ & $13(5.2 \%)$ & $11(4.4 \%)$ \\
\hline $\begin{array}{c}\text { Impaction with retained } \\
\text { deciduous }\end{array}$ & $48(9.6 \%)$ & $26(10.4 \%)$ & $22(8.8 \%)$ \\
\hline
\end{tabular}

Figure 1.

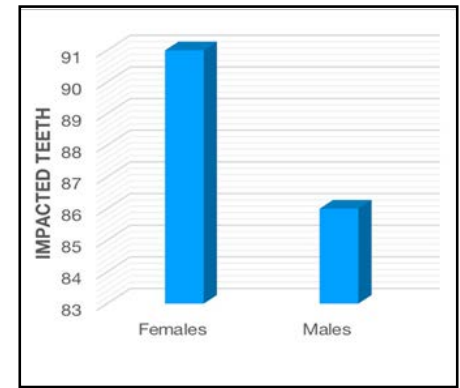

Figure 2 .

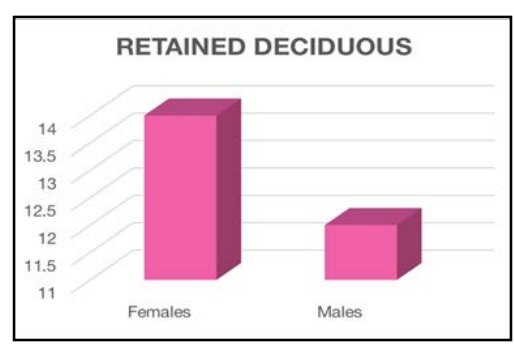


Figure 3.

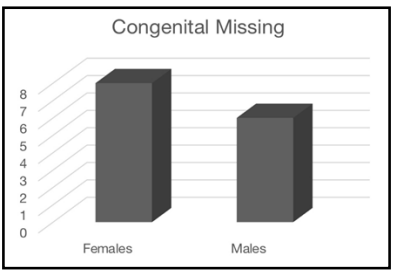

Figure 4.

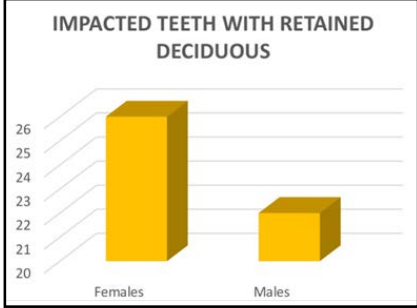

attributed primarily due to the presence of retained deciduous teeth. Maxillary and mandibular premolars and lateral incisors are most often congenitally missing. Even if present, they may follow an alternate path of eruption and become impacted as a result of spacial insufficiency in the area of eruption [5].

The aetiology behind Congenital missing of one or more teeth is unknown, but several mechanisms have been suggested like a limitation of space, physical disruption of dental lamina in the developmental stage, an inherent defect of dental lamina and failure of induction of the underlying mesenchyme. These changes are under the influence of genetic and environmental factors [6].

The clinical features of impacted teeth are mainly seen in crowded dentition, pressure resorption of roots mainly that ofthe adjacent tooth, dental caries which is occur next to partially impacted tooth, pericoronitis and pocket formation, The arch wise distribution of impaction in this study showed greater predisposition towards mandible $101(52 \%)$ than the maxilla 76 (48\%) which was in accordance with other studies by Kanneppady et al., Quek et al., which also supports our study [7, 8].

Hashemipour's study on Iranian population showed a greaterpredilectionfor the mandibular arch.These findings were in concordance with the results of the present study [9]. Cooke and Wang studied theprevalence of canine impaction and concluded that the canine is the second most commonly impacted tooth, with an incidence from $1 \%$ to $2.5 \%$. Maxillary canines can be impacted facially or palatally and are more common in female patients than in male patients, which shows similar results of our study [10].

Onyeaso et alstudy on Incidence of retained deciduous teeth in a Nigerian populationcomprising of males and females with an age range of 7-23 years had a greater prevalence of retained deciduous teethin males compared to females.But prevalence in the Indian population showed was more in females than males according to our study [11].

Sheikhi et al., studied theprevalence of congenitally missing teeth in Iranian permanent dentition was $10.9 \%$. The most common congenitally missing teeth were mandibular second premolar followed by maxillary second premolars. In this study there was no significant difference in the prevalence between males and females. The most common congenitally missing teeth were man- dibular second premolars, maxillary second premolars , maxillary lateral incisors and maxillary first premolars according to this study.According to our study the common congenital missing teeth are maxillary and mandibular premolars and lateral incisors and there was minimal significant difference in the prevalence between females $(3.2 \%)$ and males $(2.4 \%)$ [12].

Study on evaluation of factors associated with persistent primary teeth, showed that the primary mandibular second molars were the most frequently retained deciduous teeth, followed by the right and left primary maxillary canines and second molars on both sides. Therefore, primary mandibular second molars persist most often due to most common developmental absence of permanent mandibular second premolars which are their successors. Similarly, the second most common persistence rate of primary maxillary canines which leads to frequent impaction of maxillary permanent canines. In the these findings, the results of this study indicate that persistence of primary teeth may be related to developmental anomalies of their permanent successors. These results were compatible with our studies that showed the prevalence of tooth agenesis and the relationship between agenesis of permanent teeth and the persistence of primary teeth and also showed similar result the primary canines and mandibular second premolars are common retained deciduous teeth which leads to impacting of the successors teeth [13].

The most commonly impacted teeth were canines and premolars other than third molars. The rate of impactions are increased in India at an alarming rate with the progress of evolution. In the course of evolution, the tooth bud might become completely absent due to lack of space because of decrease in jaw size and loss of inter proximal attritiondue to use of refined soft diet [14].

Our study shows strong females preponderance although some studies contradict this gender predilection. This is due to early growth spurt development in females and late mineralisation .In females the end of growth spurt coincides with the onset of puberty and now the age of puberty is found to be early and this may be due to the change in dietary pattern and life style [15].

\section{Conclusion}

This study on the south Indian population analysed prevalence 
of partial anodontia and showed a greater prevalence on females compared to males. Prevalence of impaction is most common in South Indian population compared to Congenital missing and retained deciduous tooth.

\section{References}

[1]. Sivaramakrishnan SM, Ramani P. Study on the Prevalence of Eruption Status of Third Molars in South Indian Population. Biol. Med. 2015 Oct $1 ; 7(4): 245$.

[2]. Peterson LJ . Principles of Management of Impacted Teeth. In: Peterson LJ, Ellis E III, Hupp JR, Tuker MR, (eds). Contemporary Oral and Maxillofacial Surgery, (3rdedtn). St. Louis: Mosby. 1998; 215-48.

[3]. Archer WH . Oral Surgery: A Step-By-Step Atlas of Operative Techniques, W.B. Saunders Company, 4th ed. Philadelphia. 1966.

[4]. Kaur B, Sheikh S, Pallagatti S. Radiographic assessment of agenesis of third molars and para-radicular third molar radiolucencies in population of age group 18-25 years old-a radiographic survey. Arch Oral Res. 2012 Nov 28;8(1):13-18.

[5]. Agarwal KN, Gupta R, Faridi MM, Kalra N. Permanent dentition in Delhi boys of age 5-14 years. Indian Pediatr. 2004 Oct;41(10):1031-5.Pubmed PMID: 15523129

[6]. Elsey MJ, Rock WP. Influence of orthodontic treatment on development of third molars. Br J Oral Maxillofac Surg. 2000 Aug;38(4):350-3.Pubmed PMID: 10922167.

[7]. Kanneppady SK, Balamanikandasrinivasan, Kumaresan R, Sakri SB. A com- parative study on radiographic analysis of impacted third molars among three ethnic groups of patients attending AIMST Dental Institute, Malaysia. Dent Res J (Isfahan). 2013 May;10(3):353-8.Pubmed PMID: 24019804.

[8]. Quek SL, Tay CK, Tay KH, Toh SL, Lim KC. Pattern of third molar impaction in a Singapore Chinese population: a retrospective radiographic survey. Int J Oral Maxillofac Surg. 2003 Oct;32(5):548-52.Pubmed PMID: 14759117.

[9]. Hashemipour MA, Tahmasbi-Arashlow M, Fahimi-Hanzaei F. Incidence of impacted mandibular and maxillary third molars: a radiographic study in a Southeast Iran population. Med Oral Patol Oral Cir Bucal. 2013 Jan 1;18(1):e140-5.Pubmed PMID: 23229243.

[10]. Cooke J, Wang HL. Canine impactions: incidence and management. Int J Periodontics Restorative Dent. 2006 Oct 1;26(5):483-91.

[11]. Onyeaso CO. Incidence of retained deciduous teeth in a Nigerian population: an indication of poor dental awareness/attitude. Odontostomatol Trop. 2005 Sep;28(111):5-9.Pubmed PMID: 16398305.

[12]. Sheikhi M, Sadeghi MA, Ghorbanizadeh S. Prevalence of congenitally missing permanent teeth in Iran. Dent Res J (Isfahan). 2012 Dec;9(Suppl 1):105-11.Pubmed PMID: 23814548.

[13]. Aktan AM, Kara I, Sener I, Bereket C, Celik S, Kirtay M, et al. An evaluation of factors associated with persistent primary teeth. Eur J Orthod. 2012 Apr;34(2):208-12.Pubmed PMID: 21228121.

[14]. Hellman M. Our third molar teeth, their eruption, presence and absence. Dent. Cosmos. 1936;78(7):750-62.

[15]. Rajasuo A, Murtomaa H, Meurman JH. Comparison of the clinical status of third molars in young men in 1949 and in 1990. Oral Surg Oral Med Oral Pathol. 1993 Dec;76(6):694-8.Pubmed PMID: 8284072. 